\title{
Effect of education based on socio-ecological theory on bullying in students: an educational study
}

\author{
Hedayatallah Shams ${ }^{1}$, Gholamreza Garmaroudi ${ }^{2}$, Saharnaz Nedjat ${ }^{3}$, Mir Saeed Yekaninejad ${ }^{4}$
}

${ }^{1} \mathrm{PhD}$. Candidate in Health Education and Promotion, School of Health, Tehran University of Medical Sciences, Tehran, Iran

${ }^{2}$ MD, MPH Chair, Department of Health Promotion and Education; Associate Professor of Maternal and Child Health Research, School of Public Health, Tehran University of Medical Sciences, Tehran, Iran

${ }^{3}$ MD, PhD, Professor, Department of Epidemiology and Biostatistics, School of Public Health, Knowledge Utilization Research Center, Tehran University of Medical Sciences, Tehran, Iran

${ }^{4} \mathrm{PhD}$, Assistant Professor, Department of Epidemiology and Biostatistics, School of Public Health, Tehran University of Medical Sciences, Tehran, Iran

Type of article: Original

\begin{abstract}
Background: Bullying and victimization behaviors are a serious problem for students, peers, parents, and school teachers. These behaviors usually persist and cause communication problems.

Objective: To determine the effect of education based on the socio-ecological theory on bullying in students.

Methods: This educational study was of the field-trial type, and carried out on 237 middle school students in Gonabad City (Iran), from September 2015 to May 2016. The intervention group consisted of 147 students, and 90 were assigned to a control group. The intervention (Five sessions of bullying and victimization were discussed) based socio-ecological theory at two levels: individual level and interpersonal level. The intervention was carried out on the students, their parents, and school teachers in two schools. To this end, the multi-stage random sampling was done. Prior to the intervention, the Illinois questionnaire as well as a researcher-made questionnaire was completed. The researcher-made questionnaire included demographic characteristics with regard to living with both parents, one parent or no parents (a guardian) and questions about bullying behaviors in the family as well as about knowledge and attitudes towards bullying. Subsequently, the questionnaire was completed by the students one month and six months after the intervention. The data was analyzed by IBM-SPSS version 21, using ANOVA, multiple regression, repeated measures, Chi-square, and Man-Whitney U test.

Results: The findings showed that there was no significant difference between the mean attitude of the students before and after training. However, the mean score of bullying behaviors in the experimental group was significantly reduced one month after the intervention, but it increased after six months. Moreover, there was a significant difference in terms of bullying behaviors between the intervention and control groups $(\mathrm{p}=0.0001)$. Furthermore, a significant relationship was found between the mothers' education level and the students' bullying behaviors $(\mathrm{p}=0.009$

Conclusion: Bullying is an important problem that affects schools and influences the academic and social capabilities of students. In this regard, the role of educators is the most important, and education on the basis of the socio-ecological model was proved to be effective in reducing bullying. Therefore, educational intervention should be taken at two levels of school and family.

Keywords: Students, Bullying, Socio-ecological theory
\end{abstract}

\section{Corresponding author:}

Associate Professor Dr. Gholamreza Garmaroudi, Department of Health Promotion and Education, School of Public Health, Tehran University of Medical Sciences. Tel.: +98.2188989128, Email: garmaroudi@tums.ac.ir

Received: January 20, 2018, Accepted: May 15, 2018, Published: July 2018

iThenticate screening: May 09, 2018, English editing: June 02, 2018, Quality control: June 16, 2018

This article has been reviewed / commented by Four experts

Funding / research project approval: Tehran University of Medical Sciences (Ref: 8921108007, Ph.D. dissertation) Ethics approval: IR.TUMS.SPH.REC.1395.1438

(C) 2018 The Authors. This is an open access article under the terms of the Creative Commons Attribution-NonCommercialNoDerivs License, which permits use and distribution in any medium, provided the original work is properly cited, the use is non-commercial and no modifications or adaptations are made. 


\section{Introduction}

Bullying is a universal and very important problem, especially at school age. It occurs in almost all schools, and is more prevalent than what parents and teachers think. International research results, in all countries, show that between $4 \%$ and $45 \%$ of children are bullies or victims of bullying (1). This very common phenomenon is a kind of power abuse, in which the dominance of a strong person over a weaker person takes place repeatedly (2). Bullying tends to increase during middle school, peaking at around age 12, and then it generally decreases steadily (3). Although there is no general agreement on the definition of bullying, there is agreement on its features, that is, it is repetitive, unreasonable and deliberate, physical, verbal and psychological, and is committed over a person with less power. Bullying may be physical (hitting, pushing, destroying or stealing), verbal (name calling, mocking, teasing), social (excluding others from a group or spreading rumors about them), written (writing annoying or offensive notes or symbols), electronic (known as cyber bullying, such as spreading rumors and annoying comments via emails and mobile phones through text messaging and in social media sites) (4). Bullying is a global issue, which can be seen in schools. Teenagers bullying is a major international problem and 100 to 600 million young people suffer from this problem each year (5). Studies have shown that 30\% of students are involved in this issue; however, the prevalence of this problem is $72 \%$ in Tehran, Iran, among which $28 \%$ are victims, $5.9 \%$ are bullies and $34.5 \%$ are both bullies and victims (6). Research and experience have shown that bullying is a serious problem and has long-term implications for the involved students, their families, peers, and also the surrounding community. Victims or bullying children or both parties are at risk of confronting many emotional, behavioral, and relational problems, and adults should help them establish healthy relationships not only at school but also in their lives (7). Those who show bullying behaviors are more likely to have depression and those who are victims are subject to anxiety. Anxiety is one of the most common problems during adolescence (8). Bullying students usually suffer from social stress, loneliness, isolation, physical illness, and lack of self-confidence. All students who bully neither have apparent behavioral problems nor commit law-breaking activities. However, some of them skillfully have good social relationships with teachers and other adults (9). This issue is common among both genders, but varies depending on gender (10). Bullying among boys is manifested through physical and active violence associated with using inappropriate words and fighting, but among girls is often of the psychological type and associated with passive behaviors such as spreading rumors and telling tales. In the last thirty years, significant changes have been made in bullying prevention programs. The best related researches have been conducted by Scandinavian researcher Olweus who reported a 50\% reduction in bullying behaviors (11). Another research by Rigby reported that most interventions reduced bullying behaviors by about $15-20 \%$. This contradiction between the results makes it difficult to determine which methodology is more effective against bullying (12). Therefore, we needed a different solution to deal with bullying, and thus used the socio-ecological theory. The social-ecological theory (Bronfenbrenner, 1979) has been used to understand the characteristics of bullies and effects of bullying (13-15); however, it can also provide a framework for understanding how and why bullying interventions work. The use of an ecological approach to concurrently examine various systems of students' lives can provide a holistic understanding of successful bullying interventions $(15,16)$. The social-ecological theory posits that students exist and interact within a complex ecological system, consisting of three interrelated systems: microsystem, mesosystem, and macrosystem. The microsystem includes settings in which the student participates directly (e.g., home, school, peers). The mesosystem interprets relationships between microsystems, which indirectly influence students (e.g., parental involvement in education). The macrosystem, however, consists of broader social forces and structures that influence students (e.g., school or state-wide policies) (17). Because "all the ecological systems significantly influence bullying behaviors in either direct or indirect ways," (18) interventions should too (19). Researchers have suggested that anti-bullying interventions should encompass individual, solutions, such as teaching problem solving, as well as solutions involving parents, peers, teachers and the school $(19,20)$.

\section{Material and Methods}

\subsection{Research design and sampling}

This study was a field trial. Statistical population of the research included all students (4,600 participants) of secondary schools of Gonabad City (Iran) from September 2015 to May 2016. The research sample included all the 270 students of the intervention group schools, 237 of whom completed the questionnaires. Multi-stage random sampling was used in which four middle schools (two female middle schools and two male middle schools) were selected randomly at first from the four geographical districts of Gonabad city. Then, two schools (one for girls and one for boys) were assigned randomly to the experiment group and two other schools were assigned to the control group (Figure 1). Then, the interventions were performed on all students, their parents, and school teachers in the two schools. This has been supported by other researchers on bullying such as Casebeer (2012) who suggested that, 
"effective interventions required systematic, whole school initiatives" (21). Because bullying behaviors affect all students.

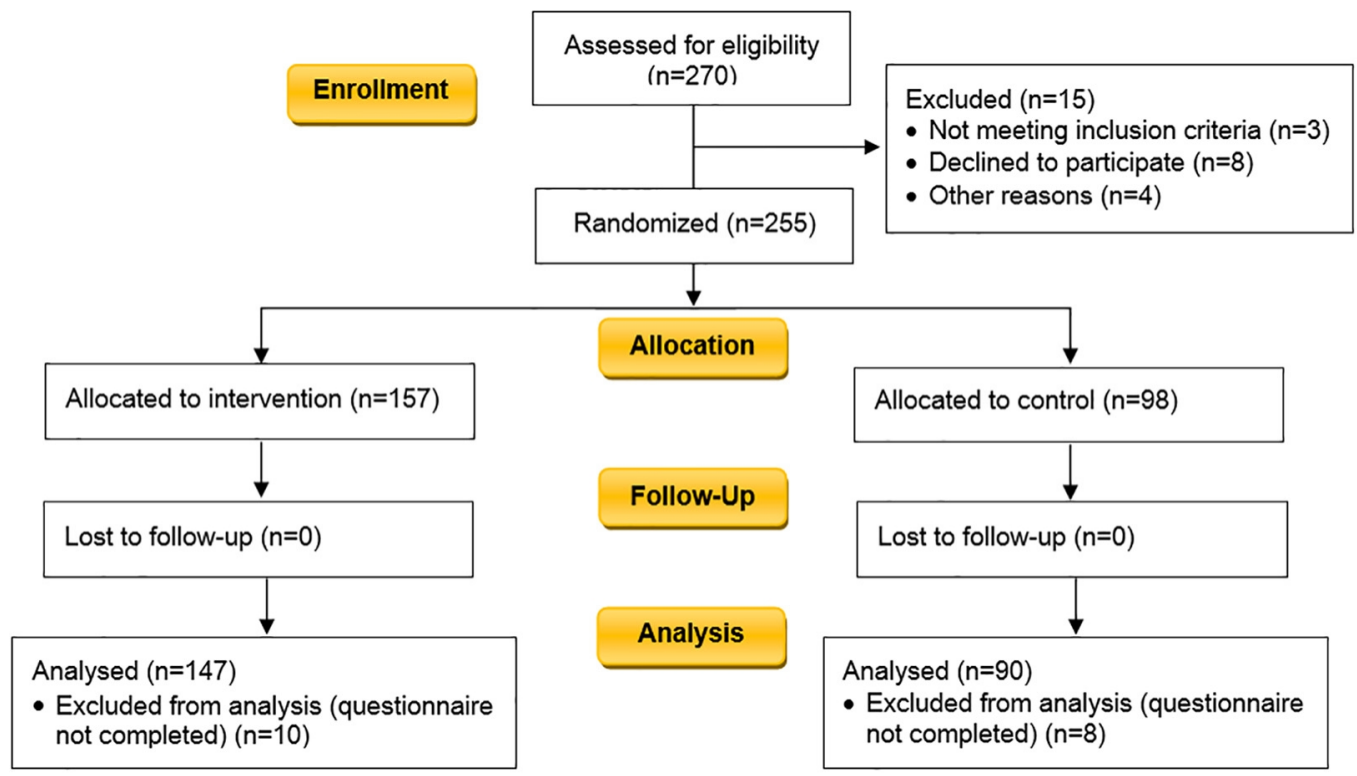

Figure 1. Flowchart of the study

\subsection{Research ethics}

The ethics Committee of Tehran University of Medical Sciences approved the ethics of the study (Ref. No.: IR.TUMS.SPH.REC.1395.1438). Primarily, the permission was obtained from the Education Office in Gonabad and the informed written consent was obtained from the parents. To conduct ethical considerations, after the intervention, the educational pamphlet was given to the control group.

\subsection{Selection criteria}

The following were set as the inclusion criteria: aged from 12 to 16 years, and not having mental illness. Exclusion criteria were the following: non-complete response to the questionnaire, and dropping-out of school.

\subsection{Instrument, its validity and reliability}

In this study, the Illinois questionnaire including 18 questions with different aspects of bullying was used. The students were asked to respond on a Likert scale of 5 point values as follows: Never=0, 1 or 2 times=1, 3 or 4 times $=2,5$ or 6 times $=3,7$ or more times $=4$. Akbari Balootbangan and Talepasand's reported Cronbach's alpha for the Illinois questionnaire was 0.87 (22). In the present study, Cronbach's alpha for the Illinois questionnaire was 0.69 ; in this questionnaire, three questions were related to bullying behavior in the family, 13 questions to knowledge, and 14 questions to attitude. The knowledge items were in the form of three choices of "Yes=2, No=1, and I do not know=0". When a person's score was lower than 14, it meant that they had no knowledge regarding bullying. The attitude items were based on a 5-point Likert scale type including completely disagree, almost disagree, have no idea, almost agree, and completely agree, to which the scores of $0,1,2,3$, and 4 were assigned, respectively. In this regard, the students who had a score lower than 14 had the negative attitude towards bullying whereas those with the score above 28 showed a positive attitude towards bullying behaviors. Prior to the intervention, the Illinois questionnaire (which measures the three areas of bullying, victimization, and fighting) along with the researcher-made questionnaire (which measured demographic characteristics with regard to living with both parents, one parent or no parents (a guardian) and questions about bullying behaviors in the family as well as about knowledge and attitudes towards bullying was administered. Content Validity Index (CVI) was used to examine the proportionality, clarity, relevance of items to the research purpose. At this stage, the tool was given to 10 experts. At this point, changes were required in terms of item deletion or item checking. Initially, by calculating CVR, each item was compared with the Lawshe table $(62 \%)$ and it was decided to keep or delete the item based on it. To determine the reliability of the researcher-made questionnaire, test-retest and Cronbach's alpha were used. Accordingly, the questionnaire was completed twice by 20 students, with a 2 -week interval. Cronbach's alpha 
measuring the internal consistency of the questionnaire was between $70 \%$ and $78 \%$, and the intra-class correlation coefficient was $71 \%$ to $77 \%$.

\subsection{Educational intervention}

The intervention included three 90-minute training sessions for students in each class, two training sessions for teachers, and two others for parents. As part of the instrument development, the draft of the questionnaire was informally reviewed by 10 practicing school psychologists to provide feedback pertaining to content, clarity of questions, and general suggestions regarding the questionnaire. The intervention was done on the basis of the socialecological theory at two levels. At the individual level, the educational intervention was performed for all the adolescents in the schools. It included knowledge, attitudes, and beliefs that affected health behaviors. Intervention at the level of the relationship with friends, peers, and families has a potential role in the formation of adolescents' behaviors. Intervention was also carried out on families because the level of knowledge of parents and teachers directly affects students. Furthermore, the intervention was conducted on teachers and school principals because school policies and laws play an important role in reducing bullying behaviors. The control group along with their teachers and families did not receive any form of instruction. Educational pamphlets were distributed among the participants in the control group after the completion of the program in order to observe ethical issues.

\subsection{Data Analysis}

The collected data were entered into IBM-SPSS Statistics version 21 (IBM- Corp., Armonk, NY, USA). At first, careful examination of the data was accomplished and the data accuracy was ensured using descriptive statistics such as mean, standard deviation, minimum and maximum values for quantitative variables and frequency distribution and percentage related to qualitative variables. Next, the Kolmogorov-Smirnov test was used to determine the normal distribution of the variables, and finally, based on the results, suitable parametric (analysis of variance, Multiple regression test, repeated measure test) and nonparametric tests (Chi-square test and MannWhitney U test) were used.

\section{Results}

Of the initial 270 students, 33 were excluded because of incomplete data. The final sample consisted of 237 subjects with a mean age of $13.73 \pm 0.93$ years old, including $151(63.7 \%)$ girls with a mean age of $13.58 \pm 0.88$ years old and $86(36.3 \%)$ boys with a mean age of $14 \pm 0.92$ years old. Moreover, $36.3 \%$ of the participants were studying in the seventh grade, $32.5 \%$ in the eighth grade and $31.2 \%$ in the ninth grade. Regarding the education level, $6.8 \%$ of the fathers were illiterate, $25.7 \%$ had elementary education, and the rest had higher education qualifications; while, $7.6 \%$ of the mothers were illiterate, $30.4 \%$ had elementary education, and $62 \%$ had higher education degrees. With regard to the economic situation, $17.3 \%$ of the sample were weak, and $6.3 \%$ had a good economic situation. Moreover, $62 \%$ of the participants were trained while $38 \%$ were not trained. In addition, $90.3 \%$ of the students lived with their parents, $1.7 \%$ with their father, $3.8 \%$ with their mother, and $4.2 \%$ in dormitories. There was no significant difference in terms of the variables between the girls and boys. However, there was a significant relationship between knowledge and bullying behaviors before and after training. In terms of bullying behaviors, $17.7 \%$ did not have bullying behaviors, $0.8 \%$ had severe bullying behaviors, $32.1 \%$ were not bullying victims, $4.6 \%$ were victims of severe bullying behaviors, $51.9 \%$ were bullying victims to some extent and $8.4 \%$ were victims of severe bullying behaviors. Moreover, $24.9 \%$ of the students were not involved in fighting, $60.3 \%$ were involved in mild fighting, $12.7 \%$ were involved in moderate fighting and $2.1 \%$ were involved in severe fighting. In terms of bully-victim behaviors, $11 \%$ of the students did not have bully-victim behaviors, $75.5 \%$ had mild bully-victim behaviors, $12.2 \%$ had moderate bully-victim behaviors, and $1.3 \%$ had severe bully-victim behaviors. The mean score of their attitude towards bullying showed no significant difference $(t=-0.72, p=0.472)$; however, there was a significant difference between the mean score of the students' knowledge about bullying before and after training (Table 1). The study of the results of Mauchly's test with $\mathrm{p}=0.036$ rejected the sphericity; thus, with no hypothesis of sphericity, we used the Correction of the Greenhouse- Geisser test. The results of the ANOVA test with repeated measures according to Table 2, showed that in the experimental group, there were not significant differences between the bullying behavior means before and after the intervention $(\mathrm{p}>0.05)$. There were also significant differences between the control and experimental groups $(\mathrm{p}<0.001)$. Therefore, education through an effective socio-ecological model is influential in reducing bullying behaviors (Table 2). 
Table 1. Frequency distribution of demographic variables in the sample

\begin{tabular}{|l|l|l|l|l|}
\hline \multirow{2}{*}{ Variable } & \multicolumn{2}{|l|}{ Male students } & \multicolumn{2}{l|}{ Female students } \\
\cline { 2 - 5 } & p-value & $\mathrm{X}^{2}$ & P-value & $\mathrm{X}^{2}$ \\
\hline Age & 0.841 & 7.242 & 0.907 & 6.167 \\
\hline Grade $\left(1^{\text {st }}\right.$ year, $2^{\text {nd }}$ year, and $3^{\text {rd }}$ year students) & 0.375 & 6.443 & 0.842 & 0.423 \\
\hline Body Mass Index & 0.691 & 2.242 & 0.644 & 1.581 \\
\hline Father education & 0.251 & 6.614 & 0.235 & 6.818 \\
\hline Mother education & 0.009 & 30.900 & 0.076 & 9.981 \\
\hline
\end{tabular}

Table 2. Comparison of the mean of bullying scores in the studied students

\begin{tabular}{|c|c|c|c|c|c|c|c|c|c|c|}
\hline \multirow[t]{4}{*}{ Bullying } & \multicolumn{6}{|c|}{ Group } & \multirow{2}{*}{\multicolumn{4}{|c|}{ RM-ANOVA }} \\
\hline & \multicolumn{3}{|c|}{ Experiment } & \multicolumn{3}{|c|}{ Control } & & & & \\
\hline & \multirow[t]{2}{*}{$\mathrm{n}$} & \multirow[t]{2}{*}{ Mean } & \multirow[t]{2}{*}{ S D } & \multirow[t]{2}{*}{$\mathrm{n}$} & \multirow[t]{2}{*}{ Mean } & \multirow[t]{2}{*}{ S D } & \multicolumn{2}{|l|}{ Time } & \multicolumn{2}{|c|}{ Time $\times$ group } \\
\hline & & & & & & & $\mathrm{F}$ & $\mathrm{P}$ & $\mathrm{F}$ & $\mathrm{P}$ \\
\hline Before intervention & 147 & 4.633 & 4.462 & 90 & 2.589 & 2.998 & & & & \\
\hline 1 month after intervention & 147 & 2.374 & 2.456 & 90 & 3.411 & 3.105 & 2.494 & 0.086 & 11.934 & 0.0001 \\
\hline 6 month later intervention & 147 & 3.082 & 3.752 & 90 & 3.244 & 4.125 & & & & \\
\hline
\end{tabular}

\section{Discussion}

Bullying is a general problem experienced by middle school students. The aim of this study was to determine the effectiveness of an educational intervention based on the social-ecological theory on high school students as well as on their parents and teachers. Intervention at the individual level was based on their knowledge, attitudes and beliefs. The findings showed that there was no significant difference between the mean score of attitude towards bullying behaviors in the control and experimental groups, but the mean score of knowledge in the experimental group was significantly different from that in the control group. Similarly, Roger stated that educational intervention increased the knowledge of students and reduced bullying behaviors, but the effect of social skill training on bullying behaviors was not significant. Moreover, Black and Jackson reported that training was effective in reducing bullying behaviors and increased knowledge and positive behaviors (23). Moreover, Neuman et al. claimed that their study increased teachers' self-efficacy in communicating with specific students and reduced their bullying behaviors. They further added that this finding was in contradiction with the supporters of the theory that considered school as a set of factors (24). The findings showed that there was a significant difference in the mean score of the girls' bullying behaviors before the training and one and six months after the training, indicating that education had a significant impact on the girls' bullying behaviors. This is while the mean score of the boys' bullying behaviors over time (before the training and one and six months after the training) was not statistically significant between the experimental and control groups. Therefore, the findings showed that training was not effective on changing the male students' bullying behaviors. There are several interpretations for this: the first is that compassion and empathy are higher in girls than in boys; the second is that girls' attitudes towards anti-bullying behaviors are more positive and they are more likely to support victims as compared to boys. Some studies have pointed out contradictory cases. Yet, some others have reported that training does not significantly lead to reduced bullying behaviors in boys and girls (25), while others have indicated that training has been effective in reducing girls' bullying behaviors (26). The changes in both the girls' and boys' victimization scores over time (before the educational intervention up to 6 months after the intervention) were not statistically significant, which contradicts the findings of Esteki et al. who pointed out that the educational program based on Olweus' method for reducing bullying had been effective in posttest and follow-up stages on victims' mean scores (27). Similarly, the results of other studies were in contrast with this finding $(28,29)$. Wang's research results showed that social-skills training was the best way to reduce bullyingvictimization behaviors and to have a proper communication with parents and friends at school (30). Moghtadaei also noted that social skill training reduced victimization behaviors (31). Intervention at the level of the relationship with friends, peers, and families has a potential role in the formation of adolescents' behaviors. There was a significant relationship between bullying behaviors in boys and the mothers' education level so that increasing the mothers' education level decreased the mean score of bullying and increased the score of victimization, which is contradictory with the findings of Healy et al. who reported that there was no significant relationship between the level of parents' education and bullying victimization behaviors of their sons (32). However, according to the findings of Cross, there was a significant relationship between parents' education level and victimization such that the score of bullying in students decreased by increasing the level of parents' education (33). Perhaps, this is due to the high level of parents' knowledge of bullying. The most important beneficiaries in society are parents and 
children's guardians; therefore, parents and children's guardians should also participate in planning and implementing bullying prevention programs (34). Hence, training them is of special importance. At school, observance of ethics, respecting each other, and promoting values and attitudes towards peers must be administered (35); this is only possible by teaching all students.

\section{Study Limitations}

One limitation of this research was self-reporting in the Illinois questionnaire. The students answered all the questions negatively by marking the never choice without paying attention to the items of the questionnaire. Moreover, the relationships among the students, colleagues, teachers, principals, and families may affect the intervention, something which was not investigated in this research. Another limitation of the present study was that the parents' and school teachers' awareness of bullying before and after the intervention was not measured; however, the parents agreed with the school administrators that they had expressed their satisfaction with regard to educational sessions held during the study.

\section{Conclusions}

Bullying is an important problem affecting students' academic and social capabilities in schools. According to the research findings, the rate of bullying declined one month after the training, but increased six months after the training. Given that, in the long run, the effect of education decreases; and for the persistence and durability of education, monthly or weekly methods for preventing bullying should be repeated for students, or life skills should be included in students' textbooks. In this regard, the role of educators is of utmost importance and in this regard, education on the basis of the socio-ecological theory was proved to be effective in reducing bullying. Thus, educational intervention should take place at school and family levels. At school level, intervention should be conducted on students and peers in order not to look at the bullying problem as a normal one and to learn ways of coping with this kind of behavior if it occurs to them or to other peers. Teachers play an important role in controlling bullying at school. Therefore, they should be trained about both bullying and effective ways of coping with it. At family level, parents should be trained about bullying and its various aspects, become familiarized with anti-bullying policies in schools, legally pursue the issue if their children are bullied, and establish more communication between parents and schools. The most important factor in reducing bullying behaviors in schools is the level of parents' education and their knowledge of bullying (especially that of mothers), which reduces bullying behaviors. Thus, educating families (particularly mothers) about bullying and thus, reducing bullying effects is of special importance.

\section{Acknowledgments:}

This article was based on the results of a Ph.D. dissertation (code 8971108007) on health education and health promotion, which was conducted at the School of Public Health, Tehran University of Medical Sciences. We are grateful to both the officials at Gonabad University of Medical Sciences and Gonabad Educational Office. Further, special thanks are forwarded to parents, teachers, and secondary-grade students in Gonabad City, who helped us with this research.

\section{Conflict of Interest:}

There is no conflict of interest to be declared.

\section{Authors' contributions:}

All authors contributed to this project and article equally. All authors read and approved the final manuscript.

\section{References:}

1) Fleming LC, Jacobsen KH. Bullying and symptoms of depression in chilean middle school students. J Sch Health. 2009; 79(3): 130-7. doi: 10.1111/j.1746-1561.2008.0397.x. PMID: 19207519.

2) Rivers I. Morbidity among bystanders of bullying behavior at school: concepts, concerns, and clinical/ research issues. Int J Adolesc Med Health. 2012; 24(1): 11-6. doi: 10.1515/ijamh.2012.003. PMID: 22909907.

3) Austin S, Reynolds G, Barnes S. School leadership and counselors working together to address bullying. Education. 2012; 2(133): 283-90.

4) Farrington DP, Ttofi MM. How to reduce school bullying. Victims and Offenders. 2009; 4(4): 321-6. doi: $10.1080 / 15564880903227255$. 
5) Volk A, Craig W, Boyce W, King M. Adolescent risk correlates of bullying and different types of victimization. Int J Adolesc Med Health. 2006; 18(4): 575-86. doi: 10.1515/IJAMH.2006.18.4.575. PMID: 17340849.

6) Garmaroudi G, Mohammad K, Omidvari S, Jafarpour S. Prevalence of Bullying and its Associated Factors among Iranian Middle School Students. Health Education \& Health Promotion. 2014; 2: 9-20.

7) Jones SE, Haslam SA, York L, Ryan MK. Rotten apple or rotten barrel? Social identity and children's responses to bullying. British Journal of Developmental Psychology. 2008; 26(1): 117-32. doi: $10.1348 / 026151007$ X200385.

8) Mohebi S, Sharifirad G, Shahsiah M, Botlani S, Matlabi M, Rezaeian M. The effect of assertiveness training on student's academic anxiety. J Pak Med Assoc. 2012; 62(3 Suppl 2): S37-41. PMID: 22768456.

9) Whitted KS, Dupper DR. Best practices for preventing or reducing bullying in schools. Children \& Schools. 2005; 27(3): 167-75. doi: 10.1093/cs/27.3.167.

10) Mahmud S, Bakar ZBA, Djaffri HB. Bullying Type in Gender Perspective in Senior High School Students, South Sulawesi Province, Indonesia. International Journal for Innovation Education and Research. 2014; 2(12): 39-47.

11) Espelage DL, Swearer SM. A social-ecological model for bullying prevention and intervention. Handbook of bullying in schools: An international perspective. 2009: 61-72.

12) Rigby K. Children and bullying: How parents and educators can reduce bullying at school. Blackwell Publishing; 2008.

13) Espelage DL, Napolitano SS. Research on school bullying and victimization: What have we learned and where do we go from here? School Psychology Review. 2003; 32: 365-83.

14) Swearer SM, Doll B. Bullying in schools: An ecological framework. Journal of Emotional Abuse. 2001; 2(213): 7-23. doi: 10.1300/J135v02n02_02.

15) Swearer SM, Espelage DL, Vaillancourt T, Hymel S. What can be done about school bullying? Linking research to educational practice. Educational researcher. 2010; 39(1): 38-47. doi: 10.3102/0013189X09357622.

16) Ayers SL, Wagaman MA, Geiger JM, Bermudez-Parsai M, Hedberg E. Examining school-based bullying interventions using multilevel discrete time hazard modeling. Prevention science. 2012; 13(5): 539-50. doi: 10.1007/s11121-012-0280-7. PMID: 22878779, PMCID: PMC3896994.

17) Lim SJJ. Bullying among refugee, immigrant and native born children in elementary and middle schools: A socio-ecological model analysis. 2012.

18) Lee $\mathrm{CH}$. Personal and interpersonal correlates of bullying behaviors among korean middle school students. Interpersonal Violence. 2010; 25(1): 152-76. doi: 10.1177/0886260508329124. PMID: 19252069.

19) Leff SS. Bullying and peer victimization at school: Considerations and future directions. School Psychology Review. 2007; 36(3): 406.

20) Mishna F, Pepler D, Wiener J. Factors associated with perceptions and responses to bullying situations by children, parents, teachers, and principals. Victims and Offenders. 2006; 1(3): 255-88. doi: $10.1080 / 15564880600626163$.

21) Casebeer CM. School bullying: Why quick fixes do not prevent school failure. Preventing school failure: Alternative education for children and youth. 2012; 56(3): 165-71. doi: 10.1080/1045988X.2011.633283.

22) Akbari Balootbangan A, Talepasand S. Validation of the Illinois bullying scale in primary school students of Semnan, Iran. Journal of fundamentals of mental health. 2015; 17(4): 178-85.

23) Rogers SL. The effectiveness of group interventions in reducing the level of bullying behaviors in middle school settings. Indiana State University; 2007.

24) Newman - Carlson D, Horne AM. Bully busters: A psychoeducational intervention for reducing bullying behavior in middle school students. Journal of Counseling \& Development. 2004; 82(3): 259-67. doi: 10.1002/j.1556-6678.2004.tb00309.x.

25) Espelage DL, Rao MA, De La Rue L. Current research on school-based bullying: A social-ecological perspective. Social Distress and the Homeless. 2013; 22(1): 21-7. doi: 10.1179/1053078913Z.0000000002.

26) Salmivalli C. Peer-led intervention campaign against school bullying: who considered it useful, who benefited? Educational Research. 2001; 43(3): 263-78. doi: 10.1080/00131880110081035.

27) Esteki Azad N, Amiri SH. Effectiveness of reduction of bullying training on the rate of victim behaviors in children. Iranian Journal of Psychiatry and Clinical Psychology. 2012; 18: 175-83.

28) Losey RA. An Evaluation of the Olweus Bullying Prevention Program's Effectiveness in a High School Setting. University of Cincinnati; 2009. 
29) Purseyed R, Amiri SH, Molavi H. Effectiveness of education programs to reduce bullying in fifth grade. Journal of Research on Exceptional Children. 2010; 10(2): 113-12.

30) Wang J, Iannotti RJ, Nansel TR. School bullying among adolescents in the United States: Physical, verbal, relational, and cyber. Journal of Adolescent health. 2009; 45(4): 368-75. doi: 10.1016/j.jadohealth.2009.03.021. PMID: 19766941, PMCID: PMC2751860.

31) MoghtadaieM, Sholeh SA, Lahijanian Z, Amin Jafari AS, Padash Z. The reduction of victim, bullying behaviors and the increase of prosocial behaviors in victim primary school boy children. Journal of Contemporary Researsh In Business. 2012; 4(2): 462-71.

32) Healy KL, Sanders MR, Iyer A. Parenting practices, children's peer relationships and being bullied at school. Journal of Child and Family Studies. 2015; 24(1): 127-40. doi: 10.1007/s10826-013-9820-4.

33) Cross D. Solution not problems: Evidence-based processes and strategies. National Coalition Against Bullying. National Conference; 2007.

34) Hornby G. Parental involvement in childhood education: Building effective school-family partnerships: Springer Science \& Business Media. 2011. doi: 10.1007/978-1-4419-8379-4.

35) Bradshaw CP, Waasdorp TE, Johnson SL. Overlapping verbal, relational, physical, and electronic forms of bullying in adolescence: influence of school context. Journal of Clinical Child \& Adolescent Psychology. 2015; 44(3): 494-508. doi: 10.1080/15374416.2014.893516. PMID: 24738548. 